\title{
Addressing the Interactive Effects of Maltreatment and COVID-19 Related Stressors on the Neuropsychological Functioning in Children
}

\author{
Natalia E. Fares-Otero* and Sebastian Trautmann \\ Department of Psychology, Medical School Hamburg, Hamburg, Germany
}

Keywords: child abuse, domestic violence, cognitive functioning, social behavior, learning, neuropsychological rehabilitation, stress, COVID-19 outbreak

\section{INTRODUCTION}

The novel coronavirus disease (COVID-19) has as of mid of October 2021, affected over 220 countries (with over 237,655,300 confirmed cases and 4,846,980 deaths; WHO, 2021a) and unprecedented disruption in the daily lives of people worldwide. Efforts to slow viral transmission, including quarantine and school closures (Baron et al., 2020; Engzell et al., 2021), have introduced profound changes in family routines and children circumstances. The conditions created by the

\section{OPEN ACCESS}

Edited by:

Maria Jose Alvarez-Alonso,

Nebrija University, Spain

Reviewed by:

Antonia Cascales-Martinez,

University of Murcia, Spain

*Correspondence:

Natalia E. Fares-Otero

natalia.fares-otero@

medicalschool-hamburg.de

Specialty section:

This article was submitted to

Neuropsychology,

a section of the journal

Frontiers in Psychology

Received: 25 August 2021 Accepted: 02 November 2021 Published: 24 November 2021

Citation:

Fares-Otero NE and Trautmann S (2021) Addressing the Interactive Effects of Maltreatment and COVID-19 Related Stressors on the Neuropsychological Functioning in Children. Front. Psychol. 12:764768.

doi: 10.3389/fpsyg.2021.764768
COVID-19 pandemic (Bridgland et al., 2021; Calvano et al., 2021; Gadermann et al., 2021) have heightened the likelihood for both life stressors (Brown et al., 2020; Griffith, 2020; Achterberg et al., 2021; Mohler-Kuo et al., 2021; Spinelli et al., 2021) and childhood maltreatment (CM; Bérubé et al., 2020; Lawson et al., 2020; Rodriguez et al., 2021; Wong et al., 2021), while clinical and social services are weakened and resources for support are reduced (Jentsch and Schnock, 2020; Usher et al., 2020).

CM is already highly prevalent and widespread (Gilbert et al., 2009; Stoltenborgh et al., 2012; Hillis et al., 2016; UNICEF, 2021). It is estimated that one out of two children aged 2-17 years old experience some form of CM each year (Hillis et al., 2016), emotional abuse affects one in three children (Stoltenborgh et al., 2012), and one in four children lives with a mother who is the victim of intimate partner violence (UNICEF, 2021). Given the lockdowns, social restrictions and living in confinement coupled with massive economic disarray, we could expect a dangerous increase in the negative consequences of CM (Garstang et al., 2020; Pereda and Díaz-Faes, 2020), affecting those who, before COVID-19, have already suffered CM, but also putting children at risk for CM who were previously unaffected. Additionally, the protective measures for preventing the spread of the virus have heightened the risk for specific types of CM [e.g., online abuse or bullying, criminal, child sexual exploitation (Kuehn, 2020), and domestic violence (Evans et al., 2020; Pereda and Díaz-Faes, 2020; Rodriguez-Jimenez et al., 2020; UN Women, 2020; Cappa and Jijon, 2021)].

The clinical implementation of measures for the detection of CM is a priority. Even with the vaccine's anticipated impact on preventing the spread of the disease, new waves of COVID-19 pandemic are hitting many parts of the world driven by new variants of the virus (WHO, 2021b). There will be long lasting health, economic, developmental, and social impacts of COVID-19. It is plausible to believe that, after COVID-19, problems will not disappear for children who will continue to suffer the consequences of this crisis. It is, therefore, critical to understand and strengthen the well-being of children with pre-existing vulnerabilities (as a history of CM), and highlight key research targets to advance our knowledge of the challenges those affected by CM and stressful events (Bridgland et al., 2021) during COVID-19 are facing (Fares-Otero et al., 2020, 2021). 
As a chronic stressor (Harkness et al., 2006; Wade et al., 2019; Rousson et al., 2020), CM contributes to alterations in the development and functioning of the brain (Teicher et al., 2012, 2016; De Brito et al., 2013; Mueller and Tronick, 2019), linked to neuropsychological deficits (Wilson et al., 2011; Samuelson et al., 2012; Spann et al., 2012; Blair et al., 2019), which lead to poor daily living skills (Kavanaugh and Holler, 2015; Meng et al., 2019), academic (Perez and Widom, 1994) and social maladjustment in children (Shonk and Cicchetti, 2001; Veltman and Browne, 2001; Stirling et al., 2008; Jaffee and MaikovichFong, 2011). Here, we propose that children exposed to CM and COVID-19 related stressors (Bridgland et al., 2021), would be more vulnerable to aggravation of neuropsychological deficits and thus, they would have higher likelihood for cognitive and social impairment through these (neuropsychological) deficits (than children without CM exposure). Therefore, it is important to identify and target neuropsychological alterations related to CM in the context of COVID-19.

\section{OPEN QUESTIONS}

Although there is strong theoretical and empirical evidence for interactive effects of CM and conditions related to the COVID19 pandemic, several important open questions remain. These include: (1) The potential dose-response relation underlying the accumulation of experienced stress types and neuropsychological risk factors during COVID-19 pandemic; (2) The interplay between effects of CM and COVID-19 stressors, examining independent contributions of co-occurring chronic and acute stress, that may contribute to the onset and maintenance of neuropsychological problems in children; and (3) Moderators of these associations including COVID-19 stressor (interpersonal violence vs. other as loss of a loved one, parental divorce) and CM type (deprivation vs. threat; Johnson et al., 2021), severity of experiences (Ouellet-Morin et al., 2019), age at onset, frequency and timing of CM (English et al., 2005) and COVID-19 stressor, gender (Sternberg et al., 2006), prior experience of CM (Guo et al., 2020), and early adverse care histories vs. current adversity, might be considered.

\section{A TAILORED NEUROPSYCHOLOGICAL REHABILITATION PROGRAM}

There is a need for specific interventions targeting neuropsychological difficulties in CM victims (Nolin and Ethier, 2007; Pechtel and Pizzagalli, 2011; Wilson et al., 2011). It is, therefore, a critical time window for the development of novel interventions for children with $\mathrm{CM}$, in order to reduce the burden and costs associated with cumulative adverse stress-related consequences of COVID-19. Neuropsychological rehabilitation (NR) is a theoretical framework and integrated approach (Wilson, 2008; Yi and Belkonen, 2011) that appears highly promising in terms of reducing neuropsychological problems in children. Within this background (see also Figure 1), we propose a NR program to guide treatment, discharge planning, and explore ways to combat neuropsychological problems tailored to the needs of children affected by CM and COVID-19 stressors.

The proposed NR program makes use of three mechanisms: (1) The child neuroplasticity allowing the brain to be malleable, i.e., cerebral mechanisms of neuronal renewal and changes $(\mathrm{Pal}$ and Elbers, 2018; Weyandt et al., 2020); (2) The preserved cognitive functions (training preserved functions may ensure correct functioning of altered ones); and (3) The resilience capacity, allowing positive adaptation in the face of adversity and environmental stressors (Charney, 2004; Masten, 2007; Cicchetti, 2013; McEwen et al., 2014; Kalisch et al., 2017). The program makes further use of classic principles of NR: compensation, substitution, and restoration or optimization (Zangwill, 1947) and integrates bottom-up and top-down approaches (Rauss and Pourtois, 2013) in three modules each of which is focused on specific (cognitive, behavioral, and social) domains: 1 . Cognitive remediation, 2. Self-regulation learning, and 3. Social skills training.

\section{Cognitive Remediation}

We propose to combine (home-based) paper-and pencil (e.g., mazes, trail-making) and computerized tasks (van der Oord et al., 2014; Corti et al., 2020; Resch et al., 2021) (optionally timed and in adapted formats), with the attention training technique (by using auditory attentional exercises; Wells, 2002), selfmonitoring attention and self-instructional training to engage children in executive control skills (Hallahan and Sapona, 1983; Diamond, 2012), selective and divided attention, and switching (Wells and Matthews, 1996; Ottowitz et al., 2002), and to increase top-down attentional control and flexibility, also related to delay gratification (Murray et al., 2018). Additionally, executive functioning can be trained by planning (e.g., using checklists, day planner, routines), management of time (limits) tasks, reasoning (e.g., analogies), spell out the rationale, and decision-making (on COVID-19 issues). It is important to encourage children to focus, remember and learn new information given, by using tasks of short duration to avoid fatigue and of a game format to avoid monotony, and to explore different ways of learning. An increased sense of the world being threatening in $\mathrm{CM}$ victims can increase child hypervigilance to (potential) threat. In addition, models of (past) threatening relationships may become activated during the COVID-19 pandemic (Kalia et al., 2020). Triggering of past traumatic memories and (possible) current ones (e.g., loss and grief) likely to be more frequent. It can be hard for children with a history of CM to place these current trauma experiences in perspective and understand that they are not permanent, and importantly, not their fault. These memories and worries could lead to attention, concentration problems and difficulty in daily planning. Children might be encouraged to manage unforeseen situations and to be flexible in order to change initial plans to adapt them to the (COVID-19) context.

\section{Self-Regulation Learning}

We propose to train self-regulation by using relaxation techniques (Ozamiz-Etxebarria et al., 2020), infant mindfulness(school)based interventions (Sibinga et al., 2013; Tao et al., 2021), and emotional modulation by means of music and 


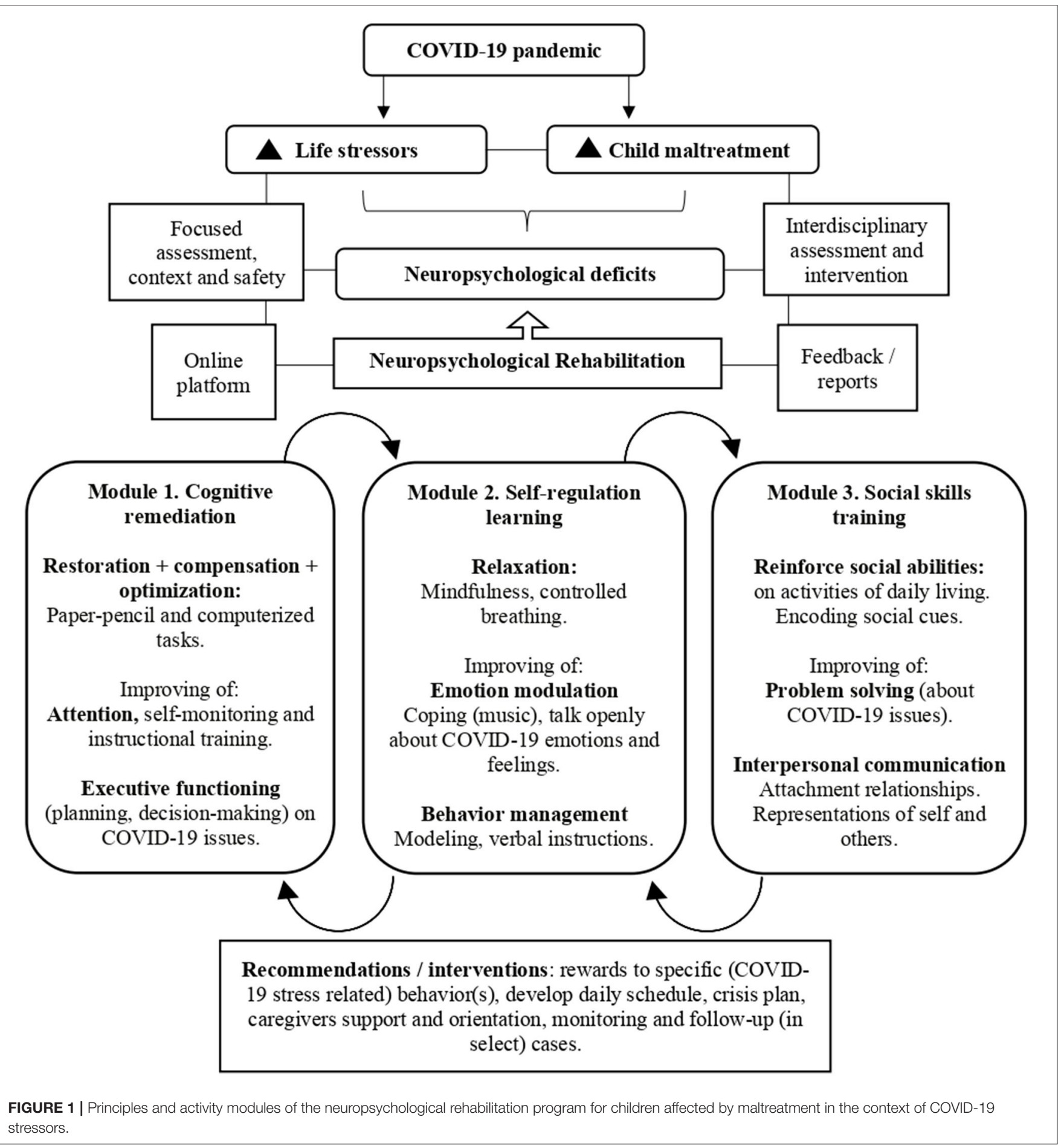

coping behavior (Hillecke et al., 2005; von Georgi et al., 2009; Steinberg et al., 2021) to reduce COVID-19 anxiety levels, and to address stress management and behavioral difficulties (inhibitory control). The world during the COVID-19 pandemic has become a much more uncertain place. This creates anxiety for all, but particularly for children who have been reared in maltreating environments where their world in the past was also deeply uncertain. The increased wariness for bad things to happen [e.g., children may worry about contagion (Muñoz-Navarro et al., 2021) or that their caregivers become ill or lose their jobs or no longer be able to look after them] could be manifested in different kinds of feelings, particularly anxiety, but also behaviors such as irritability, aggression, and withdrawal. Thus, rules and norms (on COVID-19) should be explained to address issues of safety, 
stabilize impulsive aggression against self and others, and process both the traumatic memories and trauma-related expectations (Streeck-Fischer and van der Kolk, 2000). Behavioral strategies can be included as: (a) Modeling: children are given examples of situations to demonstrate them how to react or behave; (b) Reinforcement: children are given verbalizations such as "you have done well!" or "you can do it better" as positive rewards for achievements or correct execution; (c) Verbal instructions: expected behavior has to be explained directly; and (d) Dramatization: children learn behavior while acting. Children might be asked "to talk to themselves" (Meichenbaum and Goodman, 1971) to select objectives and plan before acting, using instructions such as "think before acting" or "do it more slowly" to respond in an adaptive way, to help them to observe what is happening in present time and physically respond to current demands instead of recreating the traumatic past behaviorally and emotionally (van der Kolk, 2003).

\section{Social Skills Training}

Reinforcing social skills (in activities of daily living) can improve interpersonal communication (Cloitre et al., 2010), assertiveness, and problem solving (Tyler et al., 2021) on COVID-19 concerns. The improvement of social competence and communication involves empathy, respect of turns, verbal and non-verbal communication, by using techniques to train the performance on social skills (role-plays), to communicate and interact with each other (Ladd and Mize, 1983). The COVID-19 pandemic has had a major impact on children wider relationships. Children with $\mathrm{CM}$ have been losing out on the positive experiences of being with supportive people as friends or other family members. Differential sensitivity to the environment may have important implications for them in view of the deleterious consequences of $\mathrm{CM}$ on attachment relationships and on representations of self, caregiver and teacher. While a heightened sensitivity to social threat may be advantageous to children in the context of an adverse environment (Boyce, 2016), it can also become problematic in other situations. For instance, physically abused children are less accurate in encoding social cues, and are consequently more likely to respond aggressively to problematic social situations (Cicchetti and Valentino, 2006). The experience of CM may have meant a child was ignored and rejected, influencing their sense of self, and prior relationships with abusive adults (involving high anger exposure; Plate et al., 2019) may lead a child to believe others cannot be trusted. These vulnerabilities could be recovered through new positive experiences that encourage children to notice their strengths and weaknesses, by providing them strategies, support, and feedback (Prigatano, 1999).

\section{PRINCIPLES OF PROGRAM IMPLEMENTATION \\ Interdisciplinary Assessment and Intervention}

Interdisciplinary cooperation of child psychiatrists, pediatrists, psychologists, and social workers with experience in neuropsychological evaluation and rehabilitation is needed to address the need of CM victims in COVID-19 times. During the pandemic, children lost many sources of reward from family members, peers, and outdoor activities (Alonso-Martínez et al., 2021; de Figueiredo et al., 2021). This loose of reward may have been harder to deal with for CM victims. It is well-known that they are likely to show impairments in their reward system (Novick et al., 2018) manifested in a lack of motivation and low mood. These aspects (and maybe because of impaired attention; Boyd et al., 2019) warrant careful considerations of how to structure and deliver the proposed program.

Group sessions would allow children to practice with peers, whereas individual work promotes concentration and monitoring. Modules and tasks should be arranged based on an increasing level of difficulty, until it becomes possible for children to use the skills they would acquire (to jump to the next module). The modules should be organized to provide an order that children gradually acquire abilities that require building up from the most basic (i.e., attention) to the most demanding or complex processes (i.e., social behavior).

\section{Optimal Use of Technology}

To complement the NR program, we propose making (online) information and (psycho)education sessions available to caregivers, educators, and clinicians (joining an online consultation platform) to rapport building and provide them with information to recognize, report and respond to CM (Kimber et al., 2020; Thomas et al., 2020), the aftereffects of $\mathrm{CM}$ and clarification regarding possible cognitive, behavioral and affective changes, the rationale of the NR program, and suggestions or strategies needed (at home or the classroom) in COVID-19 times.

\section{Focused Assessment of Problem, Context, and Safety Concerns}

Besides discussing (current) neuropsychological issues, (possible) exhaustion and safety concerns might be considered. Carers of children with CM experiences always deserve particular attention, but especially so in this extraordinary period of lockdowns when caregiving in general (or cohabitation) can be extremely challenging. Within the household, parents are facing new demands with meeting basic and educational childcare needs and working remotely within in the home environment (Katz et al., 2021). We propose to review child's background, medical and developmental history, context, home environment and structure, usual and current supports. Home visiting-both in the form of physical services and remote access-should be delivered to offer children and their families appropriate professional support and to detect situations at risk for full-blown violence.

\section{Feedback, Recommendations, and Interventions}

Feedback and turn-around report addressed to the caregivers are a need. After neuropsychological assessment, caregivers may briefly sign-off, allowing the team to debrief and develop a plan. Subsequently, caregivers sign-on to receive feedback. A (short) report should be written addressed to 
the caregivers (copy to referring health clinician and to the educators), formulated in lay language, with sufficiently detailed recommendations, via email communication (provided caregiver/parental permission). Reports might include consistent responses to specific (COVID-19 stress related) behavior(s), suggestions to adapt, simplify or develop daily activity schedule, safety assessment and crisis plan, and development of beginner communication systems. Importantly, intervention efforts are needed to strengthen positive parenting behaviors (validation, connection to resources). We recommend using emotion regulation and coping strategies (as cognitive reappraisal and self-compassion; Preuss et al., 2021) to foster parent-child relationships (Skopp et al., 2007; Austin et al., 2019) during such times of heightened stress, e.g., to respect for children feelings and opinions for COVID-19 questions.

\section{DISCUSSION}

Here, we proposed a novel NR program that might be helpful to reduce neuropsychological problems in children, taking into account the special needs of children affected by $\mathrm{CM}$ and COVID-19 stressors. Childhood is a sensitive period of neurological, cognitive, social, and emotional development, during which a neuropsychological intervention can make an important difference and shift the balance between risk and protective factors (Chinitz et al., 2017).

Current research on psychosocial impacts of the COVID19 crisis has neither addressed the need for assessment and intervention targeting the neuropsychological functioning in children affected by CM. In our opinion article, we highlight the need for research aimed at a better understanding of the interactive effects of CM and COVID-19 related stressors on the neuropsychological function in children. We furthermore point out the importance of screening and monitoring $\mathrm{CM}$ and the necessity of the implementation of

\section{REFERENCES}

Achterberg, M., Dobbelaar, S., Boer, O. D., and Crone, E. A. (2021). Perceived stress as mediator for longitudinal effects of the COVID-19 lockdown on well-being of parents and children. Sci. Rep. 11:2971. doi: 10.1038/s41598-021-81720-8

Alonso-Martínez, A. M., Ramírez-Vélez, R., García-Alonso, Y., Izquierdo, M., and García-Hermoso, A. (2021). Physical activity, sedentary behavior, sleep and self-regulation in spanish preschoolers during the COVID-19 lockdown. Int. J. Environ. Res. Public Health. 18:E693. doi: 10.3390/ijerph18020693

Austin, A. E., Shanahan, M. E., Barrios, Y. V., and Macy, R. J. (2019). A systematic review of interventions for women parenting in the context of intimate partner violence. Trauma Violence Abuse. 20, 498-519. doi: 10.1177/1524838017719233

Baron, E. J., Goldstein, E. G., and Wallace, C. T. (2020). Suffering in silence: how COVID-19 school closures inhibit the reporting of child maltreatment. J. Public Econ. 190:104258. doi: 10.1016/j.jpubeco.2020.104258

Bérubé, A., Clément, M.-È., Lafantaisie, V., LeBlanc, A., Baron, M., Picher, G., et al. (2020). How societal responses to COVID-19 could contribute to child neglect. Child Abuse Negl. 2020:104761. doi: 10.1016/j.chiabu.2020.104761

Blair, K. S., Aloi, J., Crum, K., Meffert, H., White, S. F., Taylor, B. K., et al. (2019). Association of different types of childhood maltreatment with emotional responding and response control among youths. J. Am. Med. Assoc. Netw. Open 2:e194604. doi: 10.1001/jamanetworkopen.2019.4604 accurate evaluations of neuropsychological functioning in health care settings to prevent cognitive and social problems in maltreated children during and after COVID-19 pandemic and future crises.

A major challenge in our NR program is achieving a successful transfer to goal-attainment in real-life contexts. We believe that training neuropsychological functions as means to improve academic performance, is most promising in (maltreated) children, for whom both behavioral and domainspecific cognitive demands of formal schooling are quite novel challenges. An extra training and education for health professionals and educators on CM and its consequences on the neuropsychological functioning could contribute to the development of most adequate preventive and intervention measures and strengthen the collaboration between hospital services and schools.

Although the proposed NR program has a high theoretical foundation and a high potential to sustainably improve the neuropsychological functioning in children affected by CM in the context of the COVID-19 pandemic, many challenges regarding its implementation and empirical studies are needed to examine its feasibility, efficacy, and cost-effectiveness.

\section{AUTHOR CONTRIBUTIONS}

NEF-O: conceptualization, investigation, writing original draft, and writing-review and editing. ST: conceptualization, writing-review and editing, and supervision. Both authors approved the final version of the submitted manuscript.

\section{FUNDING}

NEF-O was supported by the German Academic Exchange Agency DAAD: Deutscher Akademischer Austauschdienst (91629413).

Boyce, W. T. (2016). Differential susceptibility of the developing brain to contextual adversity and stress. Neuropsychopharmacol. Off. Publ. Am. Coll. Neuropsychopharmacol. 41, 142-162. doi: 10.1038/npp.2015.294

Boyd, M., Kisely, S., Najman, J., and Mills, R. (2019). Child maltreatment and attentional problems: a longitudinal birth cohort study. Child Abuse Negl. 98:104170. doi: 10.1016/j.chiabu.2019.104170

Bridgland, V. M. E., Moeck, E. K., Green, D. M., Swain, T. L., Nayda, D. M., Matson, L. A., et al. (2021). Why the COVID-19 pandemic is a traumatic stressor. PLOS ONE 16:e0240146. doi: 10.1371/journal.pone.02 40146

Brown, S. M., Doom, J. R., Lechuga-Peña, S., Watamura, S. E., and Koppels, T. (2020). Stress and parenting during the global COVID19 pandemic. Child Abuse Negl. 110:104699. doi: 10.1016/j.chiabu.2020.10 4699

Calvano, C., Engelke, L., Di Bella, J., Kindermann, J., Renneberg, B., and Winter, S. M. (2021). Families in the COVID-19 pandemic: parental stress, parent mental health and the occurrence of adverse childhood experiences-results of a representative survey in Germany. Eur. Child Adolesc Psychiatry. 21:1739. doi: 10.1007/s00787-021-01739-0

Cappa, C., and Jijon, I. (2021). COVID-19 and violence against children: a review of early studies. Child Abuse Negl. 2021:105053. doi: 10.1016/j.chiabu.2021.105053 
Charney, D. S. (2004). Psychobiological mechanisms of resilience and vulnerability: implications for successful adaptation to extreme stress. Am. J. Psychiatry. 161, 195-216. doi: 10.1176/appi.ajp.161.2.195

Chinitz, S., Guzman, H., Amstutz, E., Kohchi, J., and Alkon, M. (2017). Improving outcomes for babies and toddlers in child welfare: a model for infant mental health intervention and collaboration. Child Abuse Negl. 70, 190-198. doi: 10.1016/j.chiabu.2017.05.015

Cicchetti, D. (2013). Annual Research Review: resilient functioning in maltreated children-past, present, and future perspectives. J. Child Psychol. Psychiatry. 54, 402-422. doi: 10.1111/j.1469-7610.2012.02608.x

Cicchetti, D., and Valentino, K. (2006). "An ecological-transactional perspective on child maltreatment: failure of the average expectable environment and its influence on child development," in Developmental Psychopathology: Risk, Disorder, and Adaptation, Vol 3, 2nd Edn. Hoboken, NJ: John Wiley \& Sons, Inc., 129-201. doi: 10.1002/9780470939406.ch4

Cloitre, M., Stovall-McClough, K. C., Nooner, K., Zorbas, P., Cherry, S., Jackson, C. L., et al. (2010). Treatment for PTSD related to childhood abuse: a randomized controlled trial. Am. J. Psychiatry. 167, 915-924. doi: 10.1176/appi.ajp.2010.09081247

Corti, C., Urgesi, C., Poggi, G., Strazzer, S., Borgatti, R., and Bardoni, A. (2020). Home-based cognitive training in pediatric patients with acquired brain injury: preliminary results on efficacy of a randomized clinical trial. Sci. Rep. 10:1391. doi: 10.1038/s41598-020-57952-5

De Brito, S. A., Viding, E., Sebastian, C. L., Kelly, P. A., Mechelli, A., Maris, H., et al. (2013). Reduced orbitofrontal and temporal grey matter in a community sample of maltreated children. J. Child Psychol. Psychiatry. 54, 105-112. doi: 10.1111/j.1469-7610.2012.02597.x

de Figueiredo, C. S., Sandre, P. C., Portugal, L. C. L., Mázala-de-Oliveira, T., da Silva Chagas, L., Raony, Í., et al. (2021). COVID-19 pandemic impact on children and adolescents' mental health: biological, environmental, and social factors. Prog. Neuropsychopharmacol. Biol. Psychiatr. 106:110171. doi: 10.1016/j.pnpbp.2020.110171

Diamond, A. (2012). Activities and programs that improve children's executive functions. Curr. Dir. Psychol. Sci. 21, 335-341. doi: 10.1177/0963721412453722

English, D. J., Graham, J. C., Litrownik, A. J., Everson, M., and Bangdiwala, S. I. (2005). Defining maltreatment chronicity: are there differences in child outcomes? Child Abuse Negl. 29, 575-595. doi: 10.1016/j.chiabu.2004.08.009

Engzell, P., Frey, A., and Verhagen, M. D. (2021). Learning loss due to school closures during the COVID-19 pandemic. Proc. Natl. Acad. Sci. U. S. A. 2021:118. doi: 10.1073/pnas.2022376118

Evans, M. L., Lindauer, M., and Farrell, M. E. (2020). A pandemic within a pandemic - intimate partner violence during covid-19. N. Engl. J. Med. 383, 2302-2304. doi: 10.1056/NEJMp,2024046

Fares-Otero, N. E., Pfaltz, M. C., Estrada-Lorenzo, J.-M., and RodriguezJimenez, R. (2020). COVID-19: the need for screening for domestic violence and related neurocognitive problems. J. Psychiatr. Res. 130, 433-434. doi: 10.1016/j.jpsychires.2020.08.015

Fares-Otero, N. E., Trautmann, S., Pfaltz, M. C., and Rodriguez-Jimenez, R. (2021). Letter to the Editor: targeting adverse stress-related consequences of the COVID-19 crisis in individuals with psychotic disorders and childhood maltreatment. J. Psychiatr. Res. 138, 453-455. doi: 10.1016/j.jpsychires.2021.04.031

Gadermann, A. C., Thomson, K. C., Richardson, C. G., Gagné M., McAuliffe, C., Hirani, S., et al. (2021). Examining the impacts of the COVID-19 pandemic on family mental health in Canada: findings from a national cross-sectional study. BMJ Open 11:e042871. doi: 10.1136/bmjopen-2020-04 2871

Garstang, J., Debelle, G., Anand, I., Armstrong, J., Botcher, E., Chaplin, H., et al. (2020). Effect of COVID-19 lockdown on child protection medical assessments: a retrospective observational study in Birmingham, UK. BMJ Open 10:e042867. doi: 10.1136/bmjopen-2020-042867

Gilbert, R., Widom, C. S., Browne, K., Fergusson, D., Webb, E., and Janson, S. (2009). Burden and consequences of child maltreatment in high-income countries. Lancet 373, 68-81. doi: 10.1016/S0140-6736(08)61706-7

Griffith, A. K. (2020). Parental burnout and child maltreatment during the COVID-19 pandemic. J. Fam. Violence 2, 1-7. doi: $10.1007 /$ s10896-020-00172-2
Guo, J., Fu, M., Liu, D., Zhang, B., Wang, X., and van IJzendoorn, M. H. (2020). Is the psychological impact of exposure to COVID-19 stronger in adolescents with pre-pandemic maltreatment experiences? A survey of rural Chinese adolescents. Child Abuse Negl. 110:104667. doi: 10.1016/j.chiabu.2020.104667

Hallahan, D. P., and Sapona, R. (1983). Self-monitoring of attention with learningdisabled children: past research and current issues. J. Learn Disabil. 16, 616-620. doi: $10.1177 / 002221948301601011$

Harkness, K. L., Bruce, A. E., and Lumley, M. N. (2006). The role of childhood abuse and neglect in the sensitization to stressful life events in adolescent depression. J. Abnorm. Psychol. 115, 730-741. doi: 10.1037/0021-843X.115.4.730

Hillecke, T., Nickel, A., and Bolay, H. V. (2005). Scientific perspectives on music therapy. Ann. N. Y. Acad. Sci. 1060, 271-282. doi: 10.1196/annals.1360.020

Hillis, S., Mercy, J., Amobi, A., and Kress, H. (2016). Global prevalence of pastyear violence against children: a systematic review and minimum estimates. Pediatrics 137:4079. doi: 10.1542/peds.2015-4079

Jaffee, S. R., and Maikovich-Fong, A. K. (2011). Effects of chronic maltreatment and maltreatment timing on children's behavior and cognitive abilities. J. Child Psychol. Psychiatr. 52, 184-194. doi: 10.1111/j.1469-7610.2010.02304.x

Jentsch, B., and Schnock, B. (2020). Child welfare in the midst of the coronavirus pandemic-emerging evidence from Germany. Child Abuse Negl. 110:104716. doi: 10.1016/j.chiabu.2020.104716

Johnson, D., Policelli, J., Li, M., Dharamsi, A., Hu, Q., and Sheridan, M. A. (2021). Associations of early-life threat deprivation with executive functioning in childhood. JAMA Pediatr. 2021:e212511. doi: 10.1001/jamapediatrics.2021.2511

Kalia, V., Knauft, K., and Hayatbini, N. (2020). Cognitive flexibility and perceived threat from COVID-19 mediate the relationship between childhood maltreatment and state anxiety. PLoS ONE 15:e0243881. doi: 10.1371/journal.pone.0243881

Kalisch, R., Baker, D. G., Basten, U., Boks, M. P., Bonanno, G. A., Brummelman, E., et al. (2017). The resilience framework as a strategy to combat stress-related disorders. Nat. Hum. Behav. 1, 784-90. doi: 10.1038/s41562-017-0200-8

Katz, C., Priolo Filho, S. R., Korbin, J., Bérubé, A., Fouché, A., Haffejee, S., et al. (2021). Child maltreatment in the time of the COVID-19 pandemic: a proposed global framework on research, policy and practice. Child Abuse Negl. 116:104824. doi: 10.1016/j.chiabu.2020.104824

Kavanaugh, B., and Holler, K. (2015). Brief report: Neurocognitive functioning in adolescents following childhood maltreatment and evidence for underlying planning and organizational deficits. Child Neuropsychol. J. Norm. Abnorm. Dev. Child Adolesc. 21, 840-848. doi: 10.1080/09297049.2014.929101

Kimber, M., McTavish, J. R., Vanstone, M., Stewart, D. E., and MacMillan, H. L. (2020). Child maltreatment online education for healthcare and social service providers: implications for the COVID-19 context and beyond. Child Abuse Negl. 2020:104743. doi: 10.1016/j.chiabu.2020.104743

Kuehn, B. M. (2020). Surge in child abuse, harm during COVID-19 pandemic reported. J. Am. Med. Assoc. 324:621. doi: 10.1001/jama.2020.14433

Ladd, G. W., and Mize, J. (1983). A cognitive-social learning model of social-skill training. Psychol. Rev. 90, 127-157. doi: 10.1037/0033-295X.90.2.127

Lawson, M., Piel, M. H., and Simon, M. (2020). Child maltreatment during the COVID-19 pandemic: consequences of parental job loss on psychological and physical abuse towards children. Child Abuse Negl. 110:104709. doi: 10.1016/j.chiabu.2020.104709

Masten, A. S. (2007). Resilience in developing systems: progress and promise as the fourth wave rises. Dev. Psychopathol. 19, 921-930. doi: $10.1017 /$ S0954579407000442

McEwen, B. S., Gray, J. D., and Nasca, C. (2014). Recognizing resilience: learning from the effects of stress on the brain. Neurobiol. Stress 1, 1-11. doi: 10.1016/j.ynstr.2014.09.001

Meichenbaum, D. H., and Goodman, J. (1971). Training impulsive children to talk to themselves: a means of developing self-control. J. Abnorm. Psychol. 77, 115-126. doi: 10.1037/h0030773

Meng, X., Gao, S., Liu, W., Zhang, L., Suo, T., and Li, H. (2019). The childhood maltreatment modulates the impact of negative emotional stimuli on conflict resolution. Front. Psychol. 10:845. doi: 10.3389/fpsyg.2019.00845

Mohler-Kuo, M., Dzemaili, S., Foster, S., Werlen, L., and Walitza, S. (2021). Stress and mental health among children/adolescents, their parents, and young adults 
during the first COVID-19 lockdown in Switzerland. Int. J. Environ. Res. Public Health 18:4668. doi: 10.3390/ijerph18094668

Mueller, I., and Tronick, E. (2019). Early life exposure to violence: developmental consequences on brain and behavior. Front. Behav. Neurosci. 13:156. doi: $10.3389 /$ fnbeh.2019.00156

Muñoz-Navarro, R., Malonda, E., Llorca-Mestre, A., Cano-Vindel, A., and Fernández-Berrocal, P. (2021). Worry about COVID-19 contagion and general anxiety: moderation and mediation effects of cognitive emotion regulation. $J$. Psychiatr. Res. 137, 311-318. doi: 10.1016/j.jpsychires.2021.03.004

Murray, J., Scott, H., Connolly, C., and Wells, A. (2018). The attention training technique improves children's ability to delay gratification: a controlled comparison with progressive relaxation. Behav. Res. Ther. 104, 1-6. doi: 10.1016/j.brat.2018.02.003

Nolin, P., and Ethier, L. (2007). Using neuropsychological profiles to classify neglected children with or without physical abuse. Child Abuse Negl. 31, 631-643. doi: 10.1016/j.chiabu.2006.12.009

Novick, A. M., Levandowski, M. L., Laumann, L. E., Philip, N. S., Price, L. H., and Tyrka, A. R. (2018). The effects of early life stress on reward processing. J. Psychiatr. Res. 101, 80-103. doi: 10.1016/j.jpsychires.2018.02.002

Ottowitz, W. E., Tondo, L., Dougherty, D. D., and Savage, C. R. (2002). The neural network basis for abnormalities of attention and executive function in major depressive disorder: implications for application of the medical disease model to psychiatric disorders. Harv. Rev. Psychiatr. 10, 86-99. doi: $10.1080 / 10673220216210$

Ouellet-Morin, I., Robitaille, M.-P., Langevin, S., Cantave, C., Brendgen, M., and Lupien, S. J. (2019). Enduring effect of childhood maltreatment on cortisol and heart rate responses to stress: the moderating role of severity of experiences. Dev. Psychopathol. 31, 497-508. doi: 10.1017/S0954579418000123

Ozamiz-Etxebarria, N., Santamaría, M. D., Munitis, A. E., and Gorrotxategi, M. P. (2020). Reduction of COVID-19 anxiety levels through relaxation techniques: a study carried out in northern spain on a sample of young university students. Front. Psychol. 11:609098. doi: 10.3389/fpsyg.2020.609098

Pal, R., and Elbers, J. (2018). Neuroplasticity: the other side of the coin. Pediatr. Neurol. 84:9. doi: 10.1016/j.pediatrneurol.2018.03.009

Pechtel, P., and Pizzagalli, D. A. (2011). Effects of early life stress on cognitive and affective function: an integrated review of human literature. Psychopharmacology. 214, 55-70. doi: 10.1007/s00213-010-2009-2

Pereda, N., and Díaz-Faes, D. A. (2020). Family violence against children in the wake of COVID-19 pandemic: a review of current perspectives and risk factors. Child Adolesc. Psychiatry Ment. Health 14:40. doi: 10.1186/s13034-020-00347-1

Perez, C. M., and Widom, C. S. (1994). Childhood victimization and longterm intellectual and academic outcomes. Child Abuse Negl. 18, 617-633. doi: 10.1016/0145-2134(94)90012-4

Plate, R. C., Bloomberg, Z., Bolt, D. M., Bechner, A. M., Roeber, B. J., and Pollak, S. D. (2019). Abused children experience high anger exposure. Front. Psychol. 10:440. doi: 10.3389/fpsyg.2019.00440

Preuss, H., Capito, K., van Eickels, R. L., Zemp, M., and Kolar, D. R. (2021). Cognitive reappraisal and self-compassion as emotion regulation strategies for parents during COVID-19: an online randomized controlled trial. Internet. Interv. 24:100388. doi: 10.1016/j.invent.2021.100388

Prigatano, G. P. (1999). Principles of Neuropsychological Rehabilitation. New York, NY: Oxford University Press, 356.

Rauss, K., and Pourtois, G. (2013). What is bottom-up and what is top-down in predictive coding? Front. Psychol. 4:276. doi: 10.3389/fpsyg.2013.00276

Resch, C., Hurks, P., de Kloet, A., and van Heugten, C. (2021). Rationale and description of BrainLevel: computerized repeated practice with strategy use instruction for children with acquired brain injury. Clin. Rehabil. 35, 787-800. doi: $10.1177 / 0269215521989652$

Rodriguez, C. M., Lee, S. J., Ward, K. P., and Pu, D. F. (2021). The perfect storm: hidden risk of child maltreatment during the covid-19 pandemic. Child Maltreat. 26, 139-151. doi: 10.1177/1077559520982066

Rodriguez-Jimenez, R., Fares-Otero, N. E., and García-Fernández, L. (2020). Gender-based violence during COVID-19 outbreak in Spain. Psychol. Med. 2020, 1-5. doi: 10.1017/S0033291720005024

Rousson, A. N., Fleming, C. B., and Herrenkohl, T. I. (2020). Childhood maltreatment and later stressful life events as predictors of depression: a test of the stress sensitization hypothesis. Psychol. Violence 10, 493-500. doi: $10.1037 /$ vio0000303
Samuelson, K. W., Krueger, C. E., and Wilson, C. (2012). Relationships between maternal emotion regulation, parenting, and children's executive functioning in families exposed to intimate partner violence. J. Interpers. Violence 27, 3532-3550. doi: $10.1177 / 0886260512445385$

Shonk, S. M., and Cicchetti, D. (2001). Maltreatment, competency deficits, and risk for academic and behavioral maladjustment. Dev. Psychol. 37, 3-17. doi: 10.1037/0012-1649.37.1.3

Sibinga, E. M. S., Perry-Parrish, C., Chung, S., Johnson, S. B., Smith, M., and Ellen, J. M. (2013). School-based mindfulness instruction for urban male youth: a small randomized controlled trial. Prev. Med. 57, 799-801. doi: 10.1016/j.ypmed.2013.08.027

Skopp, N. A., McDonald, R., Jouriles, E. N., and Rosenfield, D. (2007). Partner aggression and children's externalizing problems: maternal and partner warmth as protective factors. J. Fam. Psychol. J. Div. Fam. Psychol. Am. Psychol. Assoc. Div. 21, 459-467. doi: 10.1037/0893-3200.21.3.459

Spann, M. N., Mayes, L. C., Kalmar, J. H., Guiney, J., Womer, F. Y., Pittman, B., et al. (2012). Childhood abuse and neglect and cognitive flexibility in adolescents. Child Neuropsychol. 18, 182-189. doi: 10.1080/09297049.2011.595400

Spinelli, M., Lionetti, F., Setti, A., and Fasolo, M. (2021). Parenting stress during the COVID-19 outbreak: socioeconomic and environmental risk factors and implications for children emotion regulation. Fam. Process 60, 639-653. doi: 10.1111/famp.12601

Steinberg, S., Liu, T., and Lense, M. D. (2021). Musical engagement and parent-child attachment in families with young children during the covid-19 pandemic. Front. Psychol. 2021:v458u. doi: 10.31234/osf.io/v458u

Sternberg, K. J., Baradaran, L. P., Abbott, C. B., Lamb, M. E., and Guterman, E. (2006). Type of violence, age, and gender differences in the effects of family violence on children's behavior problems: a mega-analysis. Dev. Rev. 26, 89-112. doi: 10.1016/j.dr.2005.12.001

Stirling, J., Amaya-Jackson, L., and Amaya-Jackson, L. (2008). Understanding the behavioral and emotional consequences of child abuse. Pediatrics 122, 667-673. doi: 10.1542/peds.2008-1885

Stoltenborgh, M., Bakermans-Kranenburg, M. J., Alink, L. R. A., and IJzendoorn, M. H., van. (2012). The universality of childhood emotional abuse: a metaanalysis of worldwide prevalence. J. Aggress. Maltreat. Trauma 21, 870-890. doi: 10.1080/10926771.2012.708014

Streeck-Fischer, A., and van der Kolk, B. A. (2000). Down will come baby, cradle and all: diagnostic and therapeutic implications of chronic trauma on child development. Aust. N. Z. J. Psychiatr. 34, 903-918. doi: 10.1080/0004867 00265

Tao, S., Li, J., Zhang, M., Zheng, P., Lau, E. Y. H., Sun, J., et al. (2021). The effects of mindfulness-based interventions on child and adolescent aggression: a systematic review and meta-analysis. Mindfulness 12, 1301-15. doi: 10.1007/s12671-020-01570-9

Teicher, M. H., Anderson, C. M., and Polcari, A. (2012). Childhood maltreatment is associated with reduced volume in the hippocampal subfields CA3, dentate gyrus, and subiculum. Proc. Natl. Acad. Sci. U. S. A. 109, E563-E572. doi: 10.1073/pnas.1115396109

Teicher, M. H., Samson, J. A., Anderson, C. M., and Ohashi, K. (2016) The effects of childhood maltreatment on brain structure, function and connectivity. Nat. Rev. Neurosci. 17, 652-666. doi: 10.1038/nrn.20 16.111

Thomas, E. Y., Anurudran, A., Robb, K., and Burke, T. F. (2020). Spotlight on child abuse and neglect response in the time of COVID-19. Lancet Public Health 5:e371. doi: 10.1016/S2468-2667(20)30143-2

Tyler, P. M., Aitken, A. A., Ringle, J. L., Stephenson, J. M., and Mason, W. A. (2021). Evaluating social skills training for youth with trauma symptoms in residential programs. Psychol. Trauma Theory Res. Pract. Pol. 13, 104-113. doi: $10.1037 /$ tra0000589

UN Women (2020). Issue Brief: COVID-19 and Ending Violence Against Women and Girls. Gend-Based Violence. Available online at: https:// www.unwomen.org/en/digital-library/publications/2020/04/issue-briefcovid-19-and-ending-violence-against-women-and-girls (accessed May $4,2021)$.

UNICEF (2021). A Familiar Face: Violence in the Lives of Children and Adolescents. UNICEF DATA. Available online at: https://data.unicef.org/ resources/a-familiar-face/ (accessed May 4, 2021). 
Usher, K., Bhullar, N., Durkin, J., Gyamfi, N., and Jackson, D. (2020). Family violence and COVID-19: increased vulnerability and reduced options for support. Int. J. Ment. Health Nurs. 2020:12735. doi: 10.1111/inm.12735

van der Kolk, B. A. (2003). The neurobiology of childhood trauma and abuse. Child Adolesc. Psychiatr. Clin. N. Am. 12, 293-317. doi: 10.1016/S1056-4993(03)00003-8

van der Oord, S., Ponsioen, A. J. G. B., Geurts, H. M., Ten Brink, E. L., and Prins, P. J. M. (2014). A pilot study of the efficacy of a computerized executive functioning remediation training with game elements for children with ADHD in an outpatient setting: outcome on parent- and teacher-rated executive functioning and ADHD behavior. J. Atten. Disord. 18, 699-712. doi: 10.1177/1087054712453167

Veltman, M. W. M., and Browne, K. D. (2001). Three decades of child maltreatment research: implications for the school years. Trauma Violence Abuse 2, 215-239. doi: 10.1177/1524838001002003002

von Georgi, R., Göbel, M., and Gebhardt, S. (2009). "Emotion modulation by means of music and coping behaviour," in Music That Works: Contributions of Biology, Neurophysiology, Psychology, Sociology, Medicine and Musicology, eds R. Haas, and V. Brandes (Vienna: Springer), 301-319. doi: 10.1007/978-3-211-75121-3_19

Wade, M., Zeanah, C. H., Fox, N. A., Tibu, F., Ciolan, L. E., and Nelson, C. A. (2019). Stress sensitization among severely neglected children and protection by social enrichment. Nat. Commun. 10:5771. doi: 10.1038/s41467-019-13622-3

Wells, A. (2002). Emotional Disorders and Metacognition: Innovative Cognitive Therapy. Hoboken, NJ: John Wiley \& Sons, 255. doi: 10.1002/9780470713662

Wells, A., and Matthews, G. (1996). Modelling cognition in emotional disorder: the S-REF model. Behav. Res. Ther. 34, 881-888. doi: 10.1016/S0005-7967(96)00050-2

Weyandt, L. L., Clarkin, C. M., Holding, E. Z., May, S. E., Marraccini, M. E., Gudmundsdottir, B. G., et al. (2020). Neuroplasticity in children and adolescents in response to treatment intervention: a systematic review of the literature. Clin. Transl. Neurosci. 4:2514183X20974231. doi: $10.1177 / 2514183 X 20974231$

WHO (2021a). WHO Coronavirus (COVID-19) Dashboard. Available online at: https://covid19.who.int (accessed October 13, 2021).

WHO (2021b). Episode \#44. Delta Variant and Vaccines. Available online at: https://www.who.int/emergencies/diseases/novel-coronavirus-2019/media- resources/science-in-5/episode-44---delta-variant-and-vaccines (accessed July 3, 2021).

Wilson, B. A. (2008). Neuropsychological rehabilitation. Annu. Rev. Clin. Psychol. 4, 141-162. doi: 10.1146/annurev.clinpsy.4.022007.141212

Wilson, K. R., Hansen, D. J., and Li, M. (2011). The traumatic stress response in child maltreatment and resultant neuropsychological effects. Aggr. Violent Behav. 16, 87-97. doi: 10.1016/j.avb.2010.12.007

Wong, J. Y.-H., Wai, A. K.-C., Wang, M. P., Lee, J. J., Li, M., Kwok, J. Y.-Y., et al. (2021). Impact of COVID-19 on child maltreatment: income instability and parenting issues. Int. J. Environ. Res. Public Health 18:1501. doi: 10.3390/ijerph18041501

Yi, A., and Belkonen, S. (2011). "Neuropsychological rehabilitation," in Encyclopedia of Clinical Neuropsychology, eds J. S. Kreutzer, J. DeLuca, B. Caplan (New York, NY: Springer), 1766-1767. doi: 10.1007/978-0-387-79948-3_1096

Zangwill, O. L. (1947). Psychological aspects of rehabilitation in cases of brain injury. Br. J. Psychol. Gen. Sect. 37, 60-69. doi: 10.1111/j.2044-8295.1947.tb01121.x

Conflict of Interest: The authors declare that the research was conducted in the absence of any commercial or financial relationships that could be construed as a potential conflict of interest.

Publisher's Note: All claims expressed in this article are solely those of the authors and do not necessarily represent those of their affiliated organizations, or those of the publisher, the editors and the reviewers. Any product that may be evaluated in this article, or claim that may be made by its manufacturer, is not guaranteed or endorsed by the publisher.

Copyright (c) 2021 Fares-Otero and Trautmann. This is an open-access article distributed under the terms of the Creative Commons Attribution License (CC BY). The use, distribution or reproduction in other forums is permitted, provided the original author(s) and the copyright owner(s) are credited and that the original publication in this journal is cited, in accordance with accepted academic practice. No use, distribution or reproduction is permitted which does not comply with these terms. 